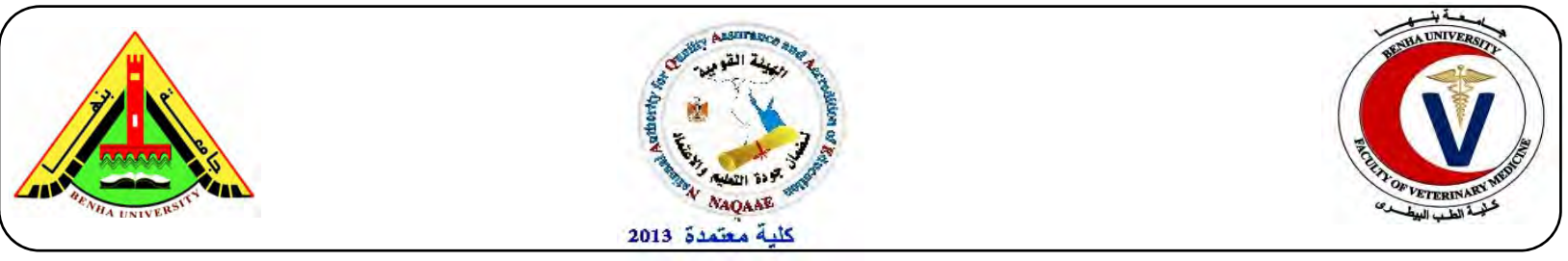

\title{
Efficacy of Acidified sodium chlorite in controlling Listeria monocytogenes in salmon fillet
}

\author{
Shireen M. Nosier ${ }^{1}$ and Mohamed A. Abdelmonem ${ }^{2}$ \\ ${ }^{1}$ Animal health research institute,${ }^{2}$ Central Laboratory of residual analysis pesticides and heavy metals \\ in food.
}

\begin{abstract}
A B S T R A C T
The purpose of this study was planned out to evaluate the effectiveness of Acidified Sodium Chlorite (ASC) on the viability of L. monocytogenes by contaminating Salmon fish samples with $1 \times 10^{8} \mathrm{cfu} / \mathrm{g}$ of $L$. monocytogenes, followed by dipping the contaminated samples in different concentrations of ASC 250, 500 and $1000 \mathrm{ppm}$. The samples were stored in refrigerator at ${ }^{\circ} 4 \mathrm{c}$ to be examined for L. monocytogenes count at Zero day ,First, third, fifth and seventh day of refrigeration storage. The results revealed that the counts of L.monocytogenes in salmon fish samples dipped in different ASC concentrations of 250, 500 and $1000 \mathrm{ppm}$ in zero (treatment day), were $1 \times 10^{7}, 3.8 \times 10^{6}$ and $1 \times 10^{6} \mathrm{cfu} / \mathrm{g}$ respectively, and in the first day after storage the counts were $8 \times 10^{6}, 1 \times 10^{6}$ and $1 \times 10^{5} \mathrm{cfu} / \mathrm{g}$ respectively while in the third, fifth and seventh day the counts were reduced to be $<10 \mathrm{cfu} / \mathrm{g}$.
\end{abstract}

Keywords: ASC, Salmon fillet, L. monocytogenes

(http://www.bvmj.bu.edu.eg)

(BVMJ-28(1): 186-190, 2015)

\section{INTRODUCTION}

C hanges in food production and demands of growing society have increased the number of incidences of food borne illness. The microbial pathogens in food are the cause of 6.5 million cases of human illness and up to 9.000 deaths in the U.S. each year (Buzhy, 2002). .Listeria. monocytogenes has been labeled as a leading of death due to food borne illness (Buzhy, 2002). L. monocytogenes has also developed as a food borne pathogen due to several other factors; one of such causes is the development of technology, which provides cold storage give adequate temperature for the growth and survival of L.monocytogenes (Richelle Lynn Beverly, 2004). The main concern of the food industry is that L.monocytigenes can grow at refrigerator temperature and is resistant to various environmental conditions (Tompkin, 2002). Sea food products might create potentiality cross contamination with L.monocytogenes. Therefore, efforts to minimize cross contaminated products are needed. The food agriculture organization reported that the cold smoked fish (Salmon fillets)have been found to be contemned with L.monocytogenes at $100 \mathrm{cfu} / \mathrm{g}$ and the temperature applied during smoking process is not sufficient to inactivate all L.monocytogenes cells in fish products (Tsui-Yin Wong, 2009). The purpose of antimicrobial agents is to reduce or eliminate microbial activity. The use of antimicrobial agents allows products to be microbial safe with the enhanced ability to extend shelf life. Consuming healthier foods is a demanding request for protection of public health and safety. Acidified sodium chlorite (ASC) is a product of the acidification of sodium chlorite (NaCLO2) using citric acid, it works by forming stable Oxychlorus antimicrobial intermediates 
(chlorite, chlorate and chlorine dioxide) as it comes into contact with organic matter (Gordon et al..1972, Kross, 1984) .ASC is applied onto the surfaces of the food at low levels. The Oxychlorine compounds are stable, and found in acidified sodium chlorite treatment solution, forming chlorite, chlorate and chlorine dioxide after mixing and after contact with food surfaces. Chlorine dioxide that forms is either evaporated or reduced without residual traces. (Food Standards Australia, Newzeland, 2003). Mixture of sodium Chlorite and citric acid forms (acidified sodium chlorite) which is applied onto food surfaces to reduce the number of microorganisms. The mix is applied by sparing or dipping. The use of sodium chlorite is technologically justified science it has a function in food as an antimicrobial agent, and there are no significant public health and safety concerns associated with its use as it have no toxicological concerns so encouraging an efficient and internationally competitive food industry (Food Standards Australia, New Zeland, 2003). The use of acidified sodium chlorite is intended as an antimicrobial intervention on a variety of raw food types to reduce the microbial contamination arising from the presence of pathogenic and spoilage species of microorganism.

\section{Material and methods}

\subsection{Bacteriological strain :}

The bacterial strain used was Listeria Monocytogenes (ATCC 35152) which obtained from the reference strain bank of Food Hygiene Department,(AHRI).

\subsection{Inoculum preparation:}

The strain was deep-frozen stored in a cryo protective vial containing preservative solution at $-70^{\circ} \mathrm{C}$, Cryobead (inoculums) of the strain was cultivated in tryptic soy broth over night at $35^{\circ} \mathrm{c}$. Then cells were centrifuged for $10 \mathrm{~min}$ at $8000 \mathrm{rpm}$. Supernatant was discarded and cells were washed three times and re-suspended in sterile $0.1 \%$ peptone water. The cells were diluted in peptone water adjusted to obtain the desired inoculums level $\left(10^{7} \mathrm{cfu} / \mathrm{ml}\right)$ (Osman, 2008).

\subsection{Preparation of Acidified Sodium Chlorite:}

Acidified sodium chlorite solution (ASC) was prepared by mixing $0.5 \mathrm{~g} / \mathrm{lof}$ sodium chlorite with $1 \mathrm{~g} / \mathrm{l}$ citric acid and the solution $\mathrm{PH}$ was 2.62 then allowed to activate for 10 minute. Then diluted with sterile distilled water to form different dilutions of 250, 500 and 1000 (ppm) with different $\mathrm{PH}(3.25,3.22$ and 3.15), the various treatments were placed in sterile containers and freshly prepared just prior examination (Inatsu, et. al., 2010). $\mathrm{Naclo}_{2}+\mathrm{H}$ (acid) $\rightarrow \mathrm{Hclo}_{2}$ (chlorous acid) $\rightarrow$ CLO (chlorine dioxide), which has antimicrobial effect.

\subsection{Sample preparation:}

Eighteen hours L.monocytogenes culture was decimally diluted to $10^{8} \mathrm{cfu} / \mathrm{ml}$ in phosphate buffer saline (PBS) solution. The salmon fish samples was cut into cubes almost equal in size and inoculated with the prepared L.monocytogenes strain, then allowed to air dry for 30 minutes in laminar flow (class $\Pi$ safety cabinet). The samples (except control) were then dipped into prepared different concentrations of Acidified Sodium Chlorite (ASC) $(250,500$ and $1000 \mathrm{ppm}$ ) for 20 minutes then left to be air dried for 30 minutes in laminar flow and kept in sterile polyethylene bags in refrigerator at $4^{\circ} \mathrm{c}$ to be examined at zero, $1^{\text {st }}, 3^{\text {rd }}, 5^{\text {th }}$ and $7^{\text {th }}$ day of storage for L.monocytogenes viable cell count. The experiment was repeated triple (FDA, 2011).

\section{Results:}


Table1: Effect of different concentrations of Acidified Sodium Chlorite (in ppm) on the viable count of inoculated L. monocytogene in salmon fish

\begin{tabular}{lllll}
\hline $\begin{array}{c}\text { Day } \\
\text { ASC }\end{array}$ & $\begin{array}{l}\text { Blank fish sample } \\
\text { Control-ve)( }\end{array}$ & $250 \mathrm{ppm}$ & $500 \mathrm{ppm}$ & $1000 \mathrm{ppm}$ \\
\hline $\begin{array}{l}\text { Zero day } \\
\text { (after } 1 \mathrm{hr})\end{array}$ & $1 \times 10^{8} \mathrm{cfu} / \mathrm{g}$ & $1 \times 10^{7} \mathrm{cfu} / \mathrm{g}$ & $3.8 \times 10^{6} \mathrm{cfu} / \mathrm{g}$ & $1 \times 10^{6} \mathrm{cfu} / \mathrm{g}$ \\
$1^{\text {st }}$ day & $5 \times 10^{9} \mathrm{cfu} / \mathrm{g}$ & $8 \times 10^{6} \mathrm{cfu} / \mathrm{g}$ & $1 \times 10^{6} \mathrm{cfu} / \mathrm{g}$ & $1 \times 10^{5} \mathrm{cfu} / \mathrm{g}$ \\
$3^{\text {rd }}$ day & $6 \times 10^{9} \mathrm{cfu} / \mathrm{g}$ & $<10 \mathrm{cfu} / \mathrm{g}$ & $<10 \mathrm{cfu} / \mathrm{g}$ & $<10 \mathrm{cfu} / \mathrm{g}$ \\
$5^{\text {th }}$ day & $2.6 \times 10^{10} \mathrm{cfu} / \mathrm{g}$ & $<10 \mathrm{cfu} / \mathrm{g}$ & $<10 \mathrm{cfu} / \mathrm{g}$ & $<10 \mathrm{cfu} / \mathrm{g}$ \\
$7^{\text {th }}$ day & $9 \times 10^{10} \mathrm{cfu} / \mathrm{g}$ & $<10 \mathrm{cfu} / \mathrm{g}$ & $<10 \mathrm{cfu} / \mathrm{g}$ & $<10 \mathrm{cfu} / \mathrm{g}$ \\
\hline
\end{tabular}

ND: Not detectable level

Fig 1: Effect of different concentration of ASC ( $\mathrm{ppm})$ on L. monocytogenes in salmon fillet:

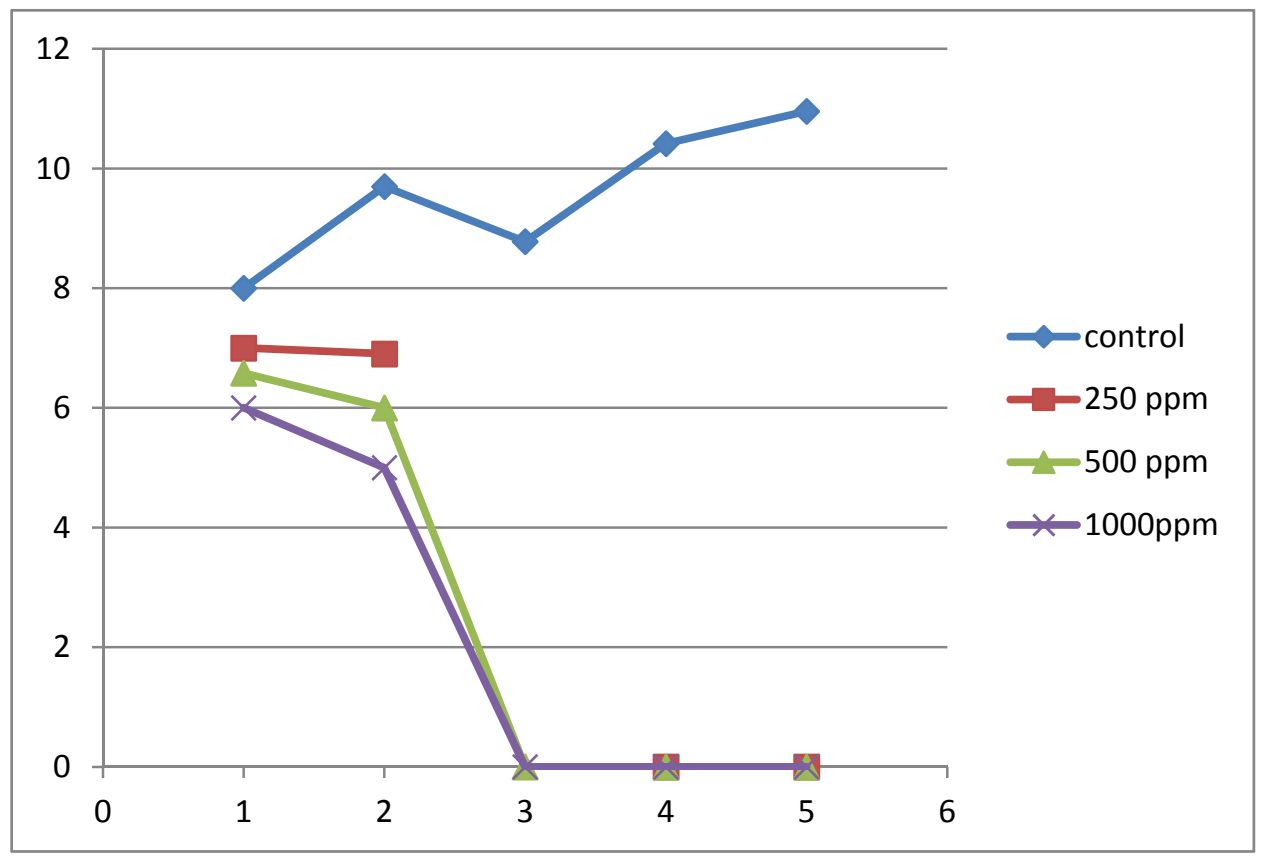

\section{DISCUSSION}

Food borne diseases and food poisoning are common throughout the world. Fresh fish is highly perishable and microbial spoilage is one of the main causes of limited shelf life and safety as well as contamination with pathogenic microorganisms by mishandling of food. Food borne illness outbreaks are a serious problem and results some times in significant death. One of the main pathogens commonly associated with seafood contamination is Listeria (Norhana et al., 2010). The use of antimicrobial agents in food processing is a way to produce safer products. Acidified Sodium Chlorite (ASC) possesses antimicrobial properties and is intended for using primarily as a spray or dipping solution for fish (Madduri V. Rao, 2007). According to 
table (1), the initial count of control samples In zero day was $1 \times 10^{8} \mathrm{cfu} / \mathrm{g}$ while count differed in the different dipped samples with different ASC concentrations. As it was $1 \times 10^{7}, 3.8 \times 10^{6}$ and $1 \times 10^{6} \mathrm{cfu} / \mathrm{g}$ in the dilutions 250,500 and $1000 \mathrm{ppm}$ respectively, while L. monocytogenes in the control sample count after the first day of refrigeration storage was $5 \times 10^{9} \mathrm{cfu} / \mathrm{g}$. While in samples were dipped in 250,500 and $1000 \mathrm{ppm}$ ASC L.momocytogene counts were of $8 \times 10^{6}, 1 \times 10^{6}$ and $1 \times 10^{5} \mathrm{cfu} /$ respectively. The control sample showed marked increase in the third day of experiment, while it was $<10 \mathrm{cfu} / \mathrm{g}$ (non detectable level) for samples dipped in ASC of the three concentrations in the third day. In the fifth and seventh day of storage L.monocytogenes increased to be $2.6 \times 10^{9}$ and $9 \times 10^{10} \mathrm{cfu} / \mathrm{g}$ respectively, While the samples dipped in 250,500 and $1000 \mathrm{ppm}$ ASC concentrations remained constant at $<10 \mathrm{cfu} / \mathrm{g}$. These results indicated that, the inoculated control fish fillet samples with L.monocytogenes showed obvious increase in their bacterial count during refrigeration storage, which approved that L.monocytogenes can stay viable and even grown well in the refrigeration temperature reaching $9 \times 10^{10} \mathrm{cfu} / \mathrm{g}$ at the end of the experiment $\operatorname{day}\left(7^{\text {th }}\right.$ day) of the study (Table1, Fig 1). These results agreed with those reported by Salyrs and Whitt (2002) who illustrated that L.monocytogenes can multiply over a wide range of temperatures, especially at refrigeration temperature. While the results of L.monocytogenes count in treated Salmon fish, fillet samples with ASC gave great indication on the effect of acidified sodium chloride (ASC) as antibacterial agent. In the beginning of this study at zero day after one hour of dipping in ASC the count decreased by one log cfu $/ \mathrm{g}$ in the $250 \mathrm{ppm}$ concentration and decreased by two logs cfu/g in samples dipped in 500 and $1000 \mathrm{ppm}$ concentration comparing to the control inoculated non treated samples. After the first day of refrigeration storge, L.monocytogenes count increased in the control samples by one $\log \mathrm{cfu} / \mathrm{g}$ to be $5 \times 10^{9} \mathrm{cfu} / \mathrm{g}$ but the treated samples L.monocytogenes count with ASC were decreased by another $3 \log$ cfu $/ \mathrm{g}$ at 250 and 500ppm, while it decreased by four log cfu/g at 1000ppm of ASC concentration as compared with control samples count under the same refrigeration conditions. At the third day of refrigeration storage, $L$. monocytogenes count reached $<10 \mathrm{cfu} / \mathrm{g}$ for all three concentrations and the same count in the fifth and seventh day of examination indicating the obvious clear inhibitory effect of ASC on the viability of L.monocytogenes in the examined fish fillet samples. Similar other studies evaluated the effectiveness of ASC as a processing aid for dipping or spraing to control L.monocytogenes aiding in the safety of ready to eat products (Beverly, 2004). Also $\mathrm{Su}$ and Morrissey (2003) reported a $0.43 \mathrm{log}$ $\mathrm{cfu} / \mathrm{cm}^{2}$ reduction of L.monocytogenes on whole Salmon washed with a $50 \mathrm{ppm}$ acidified sodium chlorite solution for one minute and found a $0.62 \log$ reduction after 7 days of storage as compared with initial count of L.monocytogenes $\left(10^{4} \mathrm{cfu} / \mathrm{g}\right)$. Beverly et.al. (2004) investigated the effect of ASC against L.monocytogenes on the surface of cooked Roost beef with different concentrations of 250,500 and $1000 \mathrm{ppm}$ ,samples had approximately $2.5 \mathrm{log} \mathrm{cfu} / \mathrm{g}$ reduction in count.

In this study, it can be concluded ASC has antimicrobial effect on L.monocytogenes by dipping and appeared in the first day of storage and increased in the third day, the use of 250 and $500 \mathrm{ppm}$ concentration of ASC is recommended as they were the concentrations which showed lesser physical changes and besides, they showed satisfactory antimicrobial effect on L.monocytogenes.

\section{REFERENCES}

Beverely, R.L. 2004. The control, survival and growth of Listeria Monocytogenes on food products. A dissertation to the graduates, Faculty 
of the Louisiana state university and agricultural and mechanical college, $\mathrm{PhD}$, department of food science Beverly,

Biolife, 2014. htp://www.biolifeitaliana.it.

Buzhy, J.C. 2002. Economics of foodborne disease L. monocytogenes, available at:

http:/www.ers.usda.gov/briefing/foo dborne disease /Listeria/.

Donnelly, C.W. 2001. Listeria Monocytogenes in guide of foodborne pathogens .Jon Wiley and sons, Inc. New York. pp. 99-132.

F.D.A. Food and drug administration .2011. Analytical manual BAM. Detection and enumeration of L.monocytogenes in foods.

Food Standards Australia, New Zeeland 2003. Application on A476 acidified sodium chlorite as a processing aid. http://www.food standards.gov.

Gordon, G., G. Kieffer, D. Rosenblatt. 1972. The chemistry of chlorine dioxide .S. Lippard (ed), progress in inorganic chem., 15:201-286, Wiely Interscience, New York.

Inatsu, Y., L. Bari, D. Nei, S. Kawasaki, S. Kawamoto. 2010. Effectiveness off different sanitizers to control Escherichia 0157:H7 on tomato surface. ISHAS act horticulture 875.

Janes, R.L., M.E., Oliver, G. 2006. Acidified sodium chlorite treatment for inhibition of L.monocytogenes growth on the surface of cooked roast beef. J food pro. 69(2): 432-5.

Kross, R. 1984. An innovation demand release micro biocide. Basis of action and effects of dilution .second biannual conference on progress in chemical disinfection, SUNY, Binghamton, New York.

LabM, 2014. http://www.labm.com.

Madduri, V. Rao. 2007. Acidified sodium chlorite (ASC) chemical and technical assessment. phd for the $68^{\text {th }}$ JECFA.

Norhana, M.N., Pool, S.E., Deeth, H.C. and Dykes, G.A. 2010. Prevalence persistence and control of Salmonella and listeria in shrimp and shrimp products. A review. Food control, 12: 343-361

Osman E. 2008. Modling the effects of sucuk production technique on listeria --monocytogenes, aerobic bacteria and lactic acid bacteria during ripening and storage food and byproducts proc. 86 : 220-226.

Salyers, A.A., D.D. white. 2002.”Listeria Monocytogenes" A doubly motile pathogen .Bacterial pathogenesis, a molecular approach, $2^{\text {nd }}$ ed. ASM press, Washington D.C.

Su, Y. and M.T. Morrissey 2003. Reducing levels of L.monocytogenes contamination on raw salmon with acidified chlorite. J. of food pro. 66(5): 812-818.

Tompkin, B.A. 2002 .Control of Listeria in food processing environment .J. of food pro. 65(4): 709-724.

Tsui-yin Wong. 2009. Antimicrobial intervention to reduce Listeria spp. Contamination on shrimp. Office of graduate students of Texas A\& M University, Ph.D. degree. 